\title{
INFORMÁTICA EDUCATIVA COMO ESPAÇO DE INCLUSÃO DIGITAL: RELATOS DA EXPERIÊNCIA DA REDE MUNICIPAL DE ENSINO DE PASSO FUNDO/RS ${ }^{1}$
}

\section{INFORMATICS EDUCATION AS AN AREA OF DIGITAL INCLUSION: REPORTS OF THE EXPERIENCE IN THE MUNICIPAL TEACHING AT PASSO FUNDO CITY}

\author{
Karina Marcon $^{2}$ \\ Adriano Canabarro Teixeira ${ }^{3}$ \\ Marco Antônio Sandini Trentin ${ }^{4}$
}

\begin{abstract}
Resumo. Por entender que as tecnologias de rede (TR) instituem uma situação de conexão generalizada e que os sujeitos podem tornar-se pólos de emissão, acredita-se que é necessário pensar em ações que proporcionem uma apropriação diferenciada das mesmas, baseada em um modelo de inclusão digital que prime pelo protagonismo e pelo reconhecimento das tecnologias como espaços comunicacionais. Frente a isto, este artigo faz o relato de algumas percepções que educadores e alunos de dez escolas municipais de Passo Fundo/RS possuem sobre as TR, decorrentes de uma experiência inclusiva de formação realizada com dez escolas do município, nos anos de 2006 e 2007, através do projeto intitulado "Formação Docente como exercício inclusivo de autoria colaborativa".

Palavras-chave: inclusão digital, formação docente, processos educativos.
\end{abstract}

\begin{abstract}
To understand that the network technologies (TR) establish a situation of widespread connection and that the subject can become focal points of issue, it is understood that it is necessary to consider actions that provide a differentiated appropriation of the same, based on a model of digital inclusion that the prime to role and the recognition of communication technologies such spaces. In front of this, this article does the reporting of some perceptions that educators and students have on the TR, stemming from an inclusive experience of training conducted with ten municipal schools of Passo Fundo/RS, in the years 2006 and 2007, through the project entitled "Teacher Training as a collaborative exercise inclusive of authorship".
\end{abstract}

Keywords: digital inclusion, teacher training, educational processes.

\section{As tecnologias na sociedade contemporânea}

Por entender que "a tecnologia é uma das características que definem a natureza humana: sua história se estende por todo o decorrer da evolução do ser humano" (CAPRA, 2002, p.97), é preciso reconhecer que elas sempre possuíram e, mais do que nunca, possuem estreitas relações com a sociedade. Desde os primeiros utensílios criados para auxiliar o homem em

1 Este artigo é um fragmento da dissertação de Mestrado realizada pela aluna Karina Marcon, com a orientação do professor. Dr. Adriano Canabarro Teixeira.

2 Mestre em Educação pela Universidade de Passo Fundo - kamarcon@ gmail.com

3 Professor do Programa de Pós-Graduação em Educação da Universidade de Passo Fundo (UPF) teixeira@upf.br

$4 \quad$ Doutor em informática aplicada à Educação/UFRGS - trentin@upf.br 
seu cotidiano até os cabos de fibra ótica, tudo é tecnologia, o que acabou por criar uma situação de estreita relação com o homem.

Frente a essa "nova compreensão da vida [...]" (p.97), acredita-se que as TR acabam potencializando uma nova estrutura social, pois através delas se estabelece uma dinâmica de rede em âmbito mundial, uma vez que as barreiras do tempo e do espaço deixam de existir simbolicamente (SERPA, 2004). As TR criam cada vez mais possibilidades e alternativas para que todos os pontos do mundo conectem-se, instituindo, assim, a chamada sociedade em rede (CASTELLS, 2005).

\subsection{Tecnologias de rede e Inclusão Digital}

A internet potencializa redes sociais, contribuindo para o estreitamento e fortalecimento das próprias relações sociais. Na contemporaneidade, considera-se que “[...] a internet é - e será ainda mais - o meio de comunicação e de relação essencial sobre o qual se baseia uma nova forma de sociedade que já vivemos" (CASTELLS, 2005, p.256), aquela que o autor chama de sociedade em rede.

Para Castells (2005, p.287), a internet constitui a base material e tecnológica da sociedade em rede, é a infra-estrutura e o meio organizativo que permite o desenvolvimento de uma série de novas formas de relações sociais, que embora não tenham origem na Internet, uma vez que são frutos de uma série de mudanças históricas, jamais poderiam se desenvolver sem a rede mundial de computadores.

Frente a essa dimensão instituída pela cibercultura, ou seja, pela cultura modificada pelo advento das TR (LEMOS, 2003), acredita-se que a prática pedagógica contemporânea pode ser potencializada a partir do diálogo e do estabelecimento de relações com as novas tecnologias. Tendo em vista o surgimento de uma nova configuração social a partir da instituição do ciberespaço como ambiente comunicacional, é preciso também pensar em uma ressignificação dos processos educacionais a partir do potencial das TR.

[...] o ciberespaço é concebido e estruturado de modo a ser, antes de tudo, um espaço social de comunicação e de trabalho em grupo. Portanto, o saber já não é mais o produto pré-construído e "midiaticamente" difundido, mas o resultado de um trabalho de construção individual ou coletivo a partir de informações ou de situações midiaticamente concebidas para oferecer ao aluno ou ao estudante oportunidades de mediação (ALAVA, 2002, p.14).

Os processos educativos imbricados a essa nova situação social estabelecem o saber como um possível resultado de construção individual ou coletiva, mediado a partir do potencial interativo existente no ciberespaço. Ressalta-se a importância do imbricamento entre processos tecnológicos e práticas educacionais, uma vez que potencializam o rompimento dos padrões tradicionais de transmissão de conhecimentos e de reprodução aos quais a escola ainda está submetida. Nesta dimensão, sobre uma pedagogia intrínseca às novas tecnologias, ressaltam-se alguns indicadores:

[...] dessa lógica e dessa pedagogia: não há centro - os processos, conforme as condições, têm uma centralidade instável. Ora o professor é o centro, ora o aluno, ora outro ator diferente de professor e aluno. Processos horizontais: - a hierarquia e a verticalidade, próprias da cultura pedagógica, são incompatíveis com a lógica e a pedagogia das Novas Tecnologias, pois estas funcionam em rede. Participação necessária - todo sujeito, para vivenciar o processo pedagógico, tem de participar na rede, sendo impraticável um mero assistir. Sincronicidade de atenção a várias coisas na aprendizagem - a profundidade não se dá através de um conceito de verticalidade, mas sim em um conceito espaço-temporal. Na verdade, é o espaço sincrônico e o tempo espacializado. Ambigüidade entre oralidade e a escrita - as 
dinâmicas comunicacionais na rede, mesmo com o uso da escrita, expressam-se com uma alta dimensão de oralidade, incluindo-se nessa expressividade as imagens. Processos coletivos necessários - sendo uma dinâmica de rede e necessitando da participação de todos, a produção é necessariamente coletiva. Cooperação como traço fundamental - para o sistema de rede funcionar, os participantes necessariamente têm que colaborar (SERPA, 2004, p.173).

A mobilidade dos centros possibilitada pelas TR - na qual ora o professor é o centro, ora o aluno - pode vir a contribuir na efetivação do processo de aprendizagem, pois estabelece uma condição de troca, cooperação, trabalho conjunto e interação, características essas que devem ser idealizadas na apropriação das tecnologias pelos educandos. Sabe-se que o educador desempenha função primordial no estabelecimento das associações cognitivas dos alunos, sendo o responsável imediato por estimular a investigação do conhecimento e, em se tratando de uma pedagogia adjacente às novas tecnologias, a postura do educador acaba por ser ressignificada porque ele deixa de ser o nó central no processo de aprendizagem, estabelecendo uma dinâmica reticular, na qual todos acabam sendo professores e alunos simultaneamente (POZO, 2002).

Pozo alerta que "estamos na sociedade da aprendizagem. Todos somos, em maior ou em menor grau, alunos e professores" (2002, p.32), e é essa atitude que diferencia a atual situação da aprendizagem na sociedade contemporânea. As práticas educacionais, portanto, precisam ser pensadas como formas por meio das quais o sujeito possa ser estimulado a participar ativa e significativamente de todos os processos de construção do conhecimento.

E frente isso, por acreditar que aconteceram significativas mudanças culturais na aprendizagem como conseqüência da evolução das tecnologias da informação e da própria organização social do conhecimento, Pozo ainda menciona que

\begin{abstract}
As novas tecnologias da informação, em vez de nos escravizar e nos submeter a suas ocas rotinas, como supunham alguns negros presságios e ainda acredita muita gente, multiplicam nossas possibilidades cognitivas e nos permitem o acesso a uma nova cultura da aprendizagem. Essas novas tecnologias não poderiam ser usadas e menos ainda planejadas se a mente humana não tivesse sido dotada com a inestimável ajuda da seleção natural, de alguns processos de aprendizagem que permitem mobilizar, ativar nossos sistemas de memória com uma eficácia realmente extraordinária (2002, p.111).
\end{abstract}

É possível verificar uma significativa relação entre as tecnologias digitais e essa mudança nos processos de aprendizagem. Acreditando que a aprendizagem é um processo essencialmente comunicativo, destaca-se o potencial das tecnologias digitais nessa situação, por suportarem ações de troca cada vez mais diversas e significativas, favorecendo a interação e a cooperação entre os sujeitos. Diante disso,

[...] Necessitamos de uma nova ordem, com base nas múltiplas culturas dos grupos humanos imersos na horizontalidade proporcionada pelo tempo espacializado, caráter estruturante das tecnologias proposicionais, e que possibilite, no espaço sincronizado, participar da produção e circulação do conhecimento (LEMOS, 2004).

Frente a isso, cada vez mais sente-se a necessidade de ações que fomentem a inclusão digital em uma dinâmica diferenciada. Inclusão digital pressupõe relações de protagonismo, autoria e co-autoria pelos sujeitos e, dessa forma, tem por objetivo fazer com que o sujeito se aproprie de estratégias comunicacionais e colaborativas que auxiliem na construção do conhecimento, de uma forma horizontal, como apontou o autor. 
Os processos comunicativos devem ser a base de sustentação dos processos educacionais. A escola como meio público de ensino da sociedade, como o legítimo espaço de educação popular, deve ser o alicerce na formação de cidadãos conscientes e preparados para viver na sociedade contemporânea, e por isso se acredita nela como instituição fundamental no desenvolvimento desses cidadãos e como espaço legítimo de inclusão digital, uma vez que é o espaço no qual a grande maioria da população tem seu primeiro contato com as tecnologias.

\section{0 projeto Formação Docente como exercício inclusivo de autoria colaborativa} A implementação do projeto Formação Docente como exercício inclusivo de autoria colaborativa surgiu de uma demanda sentida pela própria Prefeitura Municipal de Passo Fundo. A parceria entre a Universidade de Passo Fundo, através do Curso de Ciência da Computação, e a Secretaria Municipal de Educação iniciou em abril de 2005, com vistas à implantação de laboratórios de informática em dez escolas municipais.

Sentiu-se a necessidade da implementação também de um projeto piloto de formação docente, com objetivo de qualificar os educadores das escolas cujos laboratórios seriam instalados. Em novembro de 2006, foi dado início a um curso de 180 horas, cuja base conceitual foram os conceitos concernentes à inclusão digital. O projeto de formação docente foi realizado com cerca de 60 educadores através de cinco módulos. O primeiro módulo, denominado Informática Educativa na sociedade contemporânea, teve por objetivo criar uma desestabilização do grupo com relação ao papel e ao potencial das tecnologias de rede no processo de aprendizagem. Uma vez assumida a necessidade de se reconhecer como autor frente às tecnologias, os três módulos seguintes buscaram instrumentalizar os professores a fim de que pudessem, na condição de (co)autores, descobrir as possibilidades que as ferramentas oportunizam para a criação de estratégias de aprendizagem em suas escolas. (TRENTIN; TEIXEIRA; DE MARCHI; ROSSETO, 2007).

Desta forma, os módulos Utilização do Kit Escola Livre ${ }^{5}$, Internet e Pacote BrOffice foram trabalhados em uma dinâmica contextual e exploratória, ou seja, na medida em que se refletia sobre a dinâmica escolar, as ferramentas eram exploradas pelos professores, que conheciam as possibilidades de cada uma e vislumbravam inúmeros desdobramentos e apropriações (TRENTIN; TEIXEIRA; DE MARCHI; ROSSETO, 2007).

A dinâmica proposta na condução dos três módulos acima teve por objetivo possibilitar o reconhecimento de que a apropriação das tecnologias deve se dar a partir dos anseios e necessidades dos agentes do processo em uma perspectiva flexível, contextualizada e horizontal. Por fim, o último módulo, denominado Construção de projetos de aprendizagem utilizando o Kelix, visava não somente a aplicação prática dos conteúdos em suas escolas, mas, principalmente, dos processos vivenciados nos módulos pelos professores.

\subsection{As percepções de inclusão digital em dez escolas de Passo Fundo/RS}

Passado quase um ano e meio após término do Processo de Formação Docente, pareceu fundamental que se pudesse, junto aos envolvidos no processo, realizar análises e reflexões acerca das eventuais mudanças nascidas no espaço escolar decorrentes do processo de formação vivenciado, bem como detectar se, e em que medida, as TR vêm qualificando e fomentando processos de aprendizagem. Nesse sentido, foi realizada a verificação de como estavam sendo utilizados os laboratórios de informática e de que forma as crianças estavam se apropriando das tecnologias nas dez escolas participantes do projeto.

\footnotetext{
5 Solução tecnológica livre desenvolvida pelo curso de Ciência da Computação (UPF) especialmente para iniciativas de inclusão digital e informática educativa. Mais informações em http://kelix.upf.br
} 
Das dez escolas, em três os laboratórios não estavam funcionando por falta de pessoal responsável para conduzir as atividades ou por problemas de ordem técnica. Nas outras sete, foram realizadas, entrevistas com os professores responsáveis pelas atividades dos laboratórios, com os diretores e alguns alunos, bem como observações das práticas no laboratório para relacionar com o discurso vigente, verificando se os objetivos do projeto realizado pela UPF em parceria com a PMPF foram alcançados.

Os resultados dessa pesquisa foram codificados por meio de sete categorias. Em uma delas, buscava-se identificar quais eram as percepções das TR pelos professores e pelos alunos, a qual é apresentada neste artigo. Dentre suas manifestações, destacam-se as seguintes:

"Porque quadro e giz, cadeira, mesa enfileirada, é impossível se trabalhar em sala de aula [...]. Quem sabe o laboratório de informática é um atrativo como um esporte. A gente sabe que todo o adolescente, a criança, adora esporte. Então se é pra um esporte, ele vai com aquela vontade, com aquela ansiedade, até, às vezes, as aulas que antecedem a aula do esporte são vistas com pouca diferença. Então eu penso, imagina numa aula de informática, o antes ou o depois, quando a professora vai começar a trabalhar com esses alunos... acho que vai mudar muita coisa. Eu acredito ainda nessa mudança" $\left(\mathrm{P} 01^{6}\right)$.

A presença do laboratório de informática imprime novas concepções na dinâmica escolar, como pôde ser percebido na fala do professor, transcrita acima. De acordo com as observações realizadas e os relatos ouvidos, pode-se afirmar que os alunos sentem grande desejo de estar nos laboratórios utilizando os computadores e, mais do que isso, da possibilidade de estarem interagindo com o meio, ou seja, modificando e sendo modificados pela mensagem constantemente. (SILVA, 2000).

Essa questão apontada pelo professor P01 vem ao encontro da necessidade de mudanças no sistema tradicional de ensino que, por sua linearidade, não atende mais as demandas sociais atuais da chamada sociedade da aprendizagem (POZO, 2002). O professor continua:

"Acho que temos que sair do tradicional e ir pra construção de uma educação diferente. Eu acredito que essa é uma das ferramentas que vai auxiliar a fazer essa mudança, essa troca, esse passo pra avançar dentro da educação" (P01).

Portanto, esse professor, assim como o grupo do projeto de Formação Docente, acredita que a partir do potencial das tecnologias de rede se pode pensar em mudanças que contribuirão significativamente nos processos educativos. As TR possuem mecanismos que potencializam ações consideradas essenciais para um processo de aprendizagem efetivo, como a comunicação e o diálogo, elementos defendidos por Freire $(1976,1987,1988)$ e também pelos pressupostos teóricos desta pesquisa.

"Todas as pessoas deveriam entrar em contato com as novas tecnologias; porque a informática, hoje, tá em tudo. Ela nos cerca de uma maneira que tu fica pensando... De repente tu vai ao mercado ela ta lá, tu vai ao posto de gasolina ela ta lá, então não tem onde a informática não está inserida no contexto contemporâneo... tudo é

6 Em relação à categorização dos sujeitos, todas as falas identificadas como $\mathrm{P}$ são dos professores e $\mathrm{A}$ são dos alunos. Ao lado de todas elas foram colocados números - de 01 a 07 - que representam as sete escolas visitadas. Todos os sujeitos que possuem ao lado de sua letra o número 01 são da mesma escola, assim como os outros números $(02,03,04,05,06$ e 07). Essa classificação buscou facilitar a compreensão em relação a totalidade do pensamento da escola, sendo, por isso, assim mantida. 
informática e quem não souber navegar numa internet, digitar um texto, trabalhar com uma planilha eletrônica, trabalhar com arquivos, renomear, trabalhar de forma prática, não só o nosso aluno, mas todos, será considerado um analfabeto, como era antigamente, só que hoje esse analfabeto seria um analfabeto digital” (P02).

"Indispensável, porque o mundo tá caminhando pra isso... Se a gente disser analfabeto, daqui a um pouquinho um analfabeto digital vai ser um analfabeto... já é. Tem que ser isso, precisa estar em contato, porque retroceder não vai mais, é só disso pra mais... e não é só no computador [...] tudo o que a gente vê é digital... o banco tá assim, o supermercado tá assim... então é o jeito deles se inteirarem... Então a gente coloca isso pra eles: pensem onde mais vocês usam essas questões... passa no mercado e eles tão usando, vai nos terminais eletrônicos, eles têm que estar em contato isso... o nosso voto é eletrônico, então não tem...” (P03).

"Eu acho que coloca o aluno na condição dessa interação que é o mundo de hoje né, e a informática, eles tem em casa, tem a televisão, eu acho que é como dizem, alfabetizar dentro dessa área né..." (P07).

As falas desses três professores remetem à terceira lei da cibercultura, a conectividade generalizada (LEMOS, 2003). A sociedade vive em um processo de imersão tecnológica no qual muitas ações humanas são amparadas pelas tecnologias. Essa conectividade é potencializada a partir da transformação do PC em CC (computador conectado) e atualmente do CC em CC móvel (computador conectado móvel), que está cada vez mais presente no diaa-dia das pessoas, sendo popularizado principalmente pelos celulares de última geração. Para Lemos (2003), essa situação de conexão entre os mais diversos pontos possibilita a troca de informações de forma autônoma e independente, fato que colabora com a ressignificação do próprio conceito de tempo e de espaço (LEMOS, 2003; SERPA, 2004).

Em relação à situação de imersão tecnológica, a internet exerce importante papel nesse processo, pois é um ambiente midiático que transformou os processos comunicacionais (CASTELLS, 1999, 2005) potencializando cada vez mais novas e diferentes formas de ação social. Nessa dimensão, aquele que não tem contato, ou, ainda, aquele que possui contato restrito ou não se apropriou crítica e criativamente dessas tecnologias, acaba sendo um analfabeto digital - como mencionado por dois desses professores - muitas vezes até mesmo incapaz de garantir seus direitos como cidadão na contemporaneidade.

"Eu acho que auxilia o professor a explorar um contingente maior de informações. A informática dá essa possibilidade pro aluno olhar, tipo um quadro Da Vinci, dentro da área da História, dentro da área da Literatura, da própria Ciências" (P07).

"É muito importante, porque passa pro aluno essa nova visão de tecnologia, porque o aluno não tem muito contato com isso [...]. E também ele sai um pouco daquela aula muito massante, que não tem nenhuma interação, onde só tem o professor e ele ali, então é uma aula mais, digamos assim, não criativa, mas um pouco mais interessante... Não que o professor não possa dar uma aula mais interessante, o professor pode, só que eles vêem o computador assim, como algo assim fora do comum [...] porque desperta mais interesse, mais a lógica deles. Alguns programas podem despertar habilidades motoras, estratégia, raciocínio lógico, disciplina, então, existem várias habilidades e competências que o aluno pode desenvolver dentro do laboratório de informática, basta o professor trabalhar em conjunto, fazer uma coisa organizada, certa, seja por causa da internet, seja por causa dos programas que tem dentro mesmo dos computadores, aí o aluno poderá ter uma aula muito boa, revisando até assuntos diversos, dentro da sua disciplina..." (P02).

"Muitas vezes os professores vêm até o laboratório precisando de atividades para complementar o que foi dado em aula, e isso torna a informática um momento extremamente educativo, pois os alunos aprendem de forma prazerosa porque gostam muito de ir aos computadores" (P04).

Essa situação criada pela cibercultura fez surgir um novo espaço de transmissão e difusão de informações (CASTELLS, 1999; LEMOS, 2003, 2004), elementos que 
caracterizaram, de acordo com Pozo (2002), as mudanças radicais na cultura da aprendizagem. A sociedade mudou, os processos comunicacionais mudaram, influenciaram as relações humanas, portanto, os processos educativos necessariamente precisam passar por essas reconfigurações e é preciso que, por parte da escola, se compreenda essas mudanças, para depois repensar suas ações e práticas.

O laboratório de informática, na visão desses três professores citados acima, pode ser um elemento capaz de auxiliar na construção do saber, pois oferece ao aluno oportunidades e situações de mediação como foi mencionado por Alava (2002), contribuindo, assim, para o enriquecimento das aulas. Para tanto, há necessidade de adaptação e organização do professor, como mencionado por um deles, buscando as melhores formas de chegar ao que se deseja, aos objetivos do seu trabalho, pois se reconhece que potencial esses meios têm, basta pensar na forma de imbricá-los aos processos educativos.

\footnotetext{
"Aqui na escola foi um avanço enorme, até porque as crianças daqui, a maioria não têm acesso, então a gente viu o progresso que eles tiveram, eles não sabiam nem o que era o mouse, o monitor, a CPU [...], e tudo isso a gente explicou pra eles, e hoje eles sabem, então a linguagem deles aqui é a linguagem virtual [...]" (P05).

"A contribuição de solidariedade, saber dividir, coleguismo, a troca, um encontra e ensina outro, mostra pra outro, desperta... isso é contribuição. A inovação de a escola não ser só aquele ambiente chato de giz, de quadro negro, aquele professor ultrapassado e sim o professor se atualiza junto com o aluno, porque eu mesma, agora, aprendi um monte de coisas ali..." (P06).
}

Ambas as falas acreditam na inovação e no avanço da escola com a chegada do laboratório de informática. O primeiro professor menciona que após o gradual contato dos alunos com o meio, a apropriação das tecnologias fez com que passassem a utilizar a linguagem virtual, fato que existe pela ressignificação do real a partir do virtual (LÉVY, 1999), a partir da constante utilização das ferramentas comunicacionais disponíveis na internet, como blogs, chats, e-mail e sites de relacionamento, entre outras (LEMOS, 2003).

Já o segundo depoimento possibilita até mesmo autenticar o que foi mencionado por Serpa (2004) em relação a pedagogia intrínseca às novas tecnologias. Percebe-se que muitas das características apontadas pelo autor são confirmadas por esse professor, a saber: a distribuição, a participação e a colaboração, processos que permitem o funcionamento em rede, partindo de ações coletivas. Essa descentralização do saber, o fato de todos aprenderem simultaneamente, também foi uma situação apontada por Pozo (2002), que acredita que na sociedade da aprendizagem todos aprendem e todos ensinam, todos são alunos e professores.

"Então, olha, qual é a contribuição do laboratório, da internet pro aluno? Eu digo que não tem medidas... sempre sendo orientados e conduzidos, porque eles vão... eles não têm medidas, eles não têm limites e cabe a nós, que estamos aqui, limitá-los, orientá-los e incentivá-los, porque eles vão...” (P06).

Considera-se importante, na fala desse professor, seu reconhecimento sobre as capacidades cognitivas de seus alunos como seres em potencial e, indistintamente, que superam expectativas, que são capazes de aprender, são ilimitados. A professora ainda expressa que a familiarização com a linguagem digital

\footnotetext{
"não é necessária, é urgente... é pra ontem! Pra essa população aqui, que é carente, que não tem em casa, que não tem... mas que eles são sedentos, que eles querem, é ultranecessária!" (P06).
} 
Essa compreensão sobre a necessidade da familiarização com a linguagem digital confirma a necessidade que Pretto (2005) menciona sobre uma integração mais efetiva entre a educação e a comunicação.

"Muito necessária. Tanto é que eu acho mais que necessária. É o dia de hoje, não tem como fugir, é muito importante. E eles se sentem parte, mais parte do mundo, eles não se sentem assim, exclusos, eles são incluídos no mundo" (P05).

É uma necessidade recorrente, apontada em vozes unânimes que acreditam no potencial das tecnologias. Assim como Pretto (2005), esses professores crêem que a integração da comunicação na educação pode acontecer com a presença desses meios nas práticas educacionais, elementos que transformarão não só a rotina escolar, mas servirão como fundamentos de uma nova educação que atenda as necessidades contemporâneas.

Nesse processo de inclusão digital, é importante também escutar as vozes de outros elementos centrais em seu desenvolvimento, pois tão importante quanto a percepção dos professores são as expectativas dos alunos, sujeitos a quem se destinam todas as ações e pensamentos até então idealizados. Tratados como crianças que são, em uma faixa etária que compreende, neste estudo, de 8 a 10 anos, suas percepções sobre as tecnologias são muito importantes. Foi perguntado aos alunos se eles achavam importante para a própria vida saber mexer no computador, os depoimentos apontaram para uma igualdade de pensamentos:

"Sim, porque, quando eu crescer, eu posso me formar em computação" (A01).

"Sim, porque daí, de repente, quando a gente for fazer um curso, alguma coisa, quando a gente crescer mais, quando a gente for fazer um curso de enfermagem, alguma coisa, vai precisar..." (A04).

"Sim, porque eu vou aprendendo, eu posso aprender aquilo ali e ajudar os outros. [...] Se eu fosse professor eu podia dar uma aula daquilo ali" (A06).

"Sim. Porque várias vezes a gente tem que.... fazer coisas no computador. O computador é bem útil" (A02).

"É legal, porque daí a gente se interativa (sic) mais com as coisas" (A03).

"Eu acho. Bom, porque quando a gente mexe no computador a gente descobre um monte de coisa nova, a gente pode fazer o que a gente bem querer né, a gente pode jogar, pode fazer texto, a gente pode descobrir um monte de coisa. Pra mim é tudo!" (A07).

Percebe-se que os três primeiros alunos relacionam os conhecimentos em informática com seu futuro profissional. O primeiro parece demonstrar tanto desejo que pretende se formar em computação. Os outros dois subentendem que a informática é essencialmente importante para desenvolver qualquer profissão. De todos os alunos entrevistados, a última fala é do único aluno que possuía computador conectado à internet em casa. Seu depoimento dizendo que "a internet é tudo", faz pensar que essa criança efetivamente se apropriou dos meios (BONILLA, 2004), tanto que já reconhece o potencial desse meio e sabe que é um recurso que possui inúmeras possibilidades.

Ao serem questionados se o laboratório contribuía de alguma forma para o aprendizado, as respostas também foram idênticas:

"Sim, a gente aprende a escrever no computador, a gente aprende a mexer no computador, a escrever..." (A01).

"Sim, ajuda a aprender a mexer no computador, a gente fazer pesquisa... [...] é importante. Pra saber jogar quando tem um computador em casa, tem que saber mexer também" (A05).

"Acho. Porque se tu tá com alguma dúvida, ou se tu precisa dele e tu não tem em casa, acho que é melhor" (A03). 
"Sim. Pra arrumar emprego a gente tem que saber mexer no computador algumas coisas" (A02).

Essas quatro primeiras falas apontam para a contribuição no aprendizado em relação ao manuseio da máquina, mas não mencionam outras relações da informática com o elemento potencializados de construção de conceitos e compreensão de fenômenos.

\footnotetext{
"Porque a gente aprende a lidar mais no computador, a gente aprende mais a mexer com as teclas, a gente aprende mais, tipo, o que não pode fazer com os computadores... Nas pesquisas ajuda a gente, porque sempre que a gente vem aqui e que a gente pesquisa, a gente volta pra sala de aula e fala tudo sobre tudo o que a gente fez aqui na informática..." (A04).

"Sim, elas ajudam a pesquisar mais as coisas, aprende desde o corpo da gente. (A06).

"Eu acho que sim. Bom, porque a gente vai aprendendo coisa nova com o joguinho, a gente vai aprendendo a mexer, que nem as aulas de informática no centro, a gente aprende a mexer, a desenhar, a brincar, fazer um monte de coisa. Tem gente que não sabe mexer com as teclas, mas com as aulas de informática ela aprende, daí eu acho que é melhor" (A07).
}

Já essas três últimas falas dos alunos reconhecem que a informática auxilia no aprendizado, seja aquele que é iniciado em sala de aula e têm a informática como apoio, ou aquele que inicia com a informática e é retomado pelo professor em sala de aula. O que pode se perceber nas falas de todas essas crianças é que a utilização do laboratório está sendo feita de duas formas. Na primeira os professores utilizam o laboratório como um elemento a parte, talvez em momentos de recreação. Na outra os professores utilizam o laboratório para estender seus conteúdos, usando mecanismos como pesquisas para contribuir com o processo de aprendizagem do aluno em relação à conteúdos específicos.

Em uma perspectiva geral pode-se considerar que nas sete turmas e escolas observadas, existe um reconhecimento por parte dos professores e dos gestores relativos à importância da informática educativa no contexto contemporâneo, mas uma evidente carência de exploração de suas capacidades. De acordo com o que foi observado nas escolas, os laboratórios estão sendo utilizados, mas ainda existe certa ociosidade por problemas relacionados à falta de pessoal para atender a demanda. Percebeu-se que na maioria das escolas os alunos estão tendo liberdade no contato com o meio, mas muitas vezes condicionados às escolhas dos professores, movimento oriundo de um sistema tradicional e verticalizado de ensino, que impossibilita o aluno de ir além do proposto. Entretanto, diante disso, é preciso provocar uma reflexão acerca dos motivos que levam à insistência em um modo tradicional de ensino, pois essa é uma condição que vai além das possibilidades dos professores, uma vez que os mesmos se encontram em um sistema estruturado assim há muito tempo.

\section{Conclusões Parciais}

Como foi visto, as tecnologias de rede apresentam características que autorizam a democratização e a participação e precisam ser vistas como tecnologias diferenciadas, nas quais se abrem os pólos de emissão de informações, sentidos e significados. Por isso, ações que visem a uma apropriação crítica das tecnologias devem, portanto, ser fomentadas e constantemente verificadas, buscando com que realmente ocorra um avanço na democratização das tecnologias, bem como uma presença participativa do cidadão na cibercultura.

Em relação aos entendimentos dos educadores sobre informática educativa, percebeuse que todos acreditam nela como um elemento que pode contribuir significativamente nos 
processos de aprendizagem. Em todas as falas dos docentes, notou-se a existência de um fio condutor, que é, também, harmônico ao que o grupo de pesquisa docente propôs. Diante disso, menciona-se a importância de projetos de formação docente para que haja essa unidade que foi encontrada, pois acredita-se que quando um projeto é assim compreendido, possui mais força na própria execução.

Diante dos dados obtidos, tem-se a certeza de que o processo de inclusão digital da rede municipal de ensino de Passo Fundo/RS será alimentado com novas idéias, entendimentos, perspectivas e desejos. Fica, diante da experiência, do contato, da vivência, das falas, das observações, das entrevistas, o desafio de buscar sempre novas alternativas para que esse processo de inclusão digital seja constantemente renovado e que informática educativa assuma, de fato, o papel de dinamizadora de processos educativos.

\section{Referências}

ALAVA, S. Os paradoxos de um debate. Preâmbulo. In: ALAVA, Séraphin (org). Ciberespaço e formações abertas: rumo a novas práticas educacionais?. Porto Alegre: Artmed, 2002.

BONILLA, M. H. Educação e Inclusão Digital. GEC: Grupo de Pesquisa em Educação, Comunicação e Tecnologias. 2004. Disponível em <http://twiki.im.ufba.br/bin/ view/GEC/MariaHelenaBonilla>. Acesso em: 10 Out. 2007.

CAPRA, F. As conexões ocultas. Ciência para uma vida sustentável. São Paulo: Editora Pensamento - Cultrix, 2002.

CASTELLS, M. A era da Informação: Economia, Sociedade e Cultura - O Poder da Identidade. Vol.2. $3^{a}$ ed. São Paulo: Paz e Terra, 1999.

CASTELLS, M. A internet e Sociedade em Rede. In: MORAES, Dênis de (org). Por uma outra comunicação - Mídia, mundialização cultural e poder. $3^{\mathrm{a}}$ ed. Rio de Janeiro: Record, 2005.

FREIRE, P. Educação como prática da liberdade. $6^{\text {a }}$ ed. Rio de Janeiro: Paz e Terra, 1976.

FREIRE, P. Pedagogia do Oprimido. 17 ed. Rio de Janeiro: Paz e Terra, 1987.

FREIRE, P. Comunicação ou Extensão? 10ª edição. Rio de Janeiro: Paz e Terra, 1988.

LEMOS, A. Cibercultura. Alguns Pontos para compreender a nossa época. In: LEMOS, André; Cunha, Paulo (orgs). Olhares sobre a Cibercultura. Sulina: Porto Alegre, 2003.

LEMOS, A. Cibercultura e Identidade Cultural. Em direção a uma cultura copyleft? Ensaio apresentado do Fórum Cultural Mundial e no Simpósio Emoção Art. oficial (Itaú Cultural). São Paulo, julho 2004. Disponível em: <http://www.facom.ufba.br/ciberpesquisa/ andrelemos/copyleft.pdf>. Acesso em 15 Mai. 2007.

LÉVY, P. Cibercultura. São Paulo: Ed. 34, 1999.

POZO, J. I. Aprendizes e Mestres: A nova cultura da aprendizagem. Porto Alegre: Artmed Editora, 2002.

PRETTO, N. Políticas públicas educacionais no mundo contemporâneo. Liinc em revista. Março, 2005. Disponível em: <http://www.liinc.ufrj.br/revista/revista_tres/pretto.pdf>. Acesso em: 10 Jun. 2007.

SERPA, F. Rascunho Digital - Diálogos com Felippe Serpa. Salvador: Edufba, 2004.

SILVA, M. Sala de aula interativa. Rio de Janeiro: Quartet, 2000.

TRENTIN, M.; TEIXEIRA, A. C., DE MARCHI, A. B.; ROSSETO, M. C. Formação docente: um exercício de autonomia colaborativa. RENOTE - Revista Novas Tecnologias na Educação, Nov. 2007. 